IBM Business Consulting Services

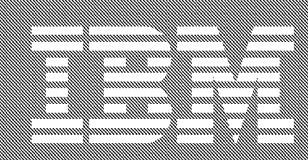

\title{
Supply chain management
}

New competitive realities in the automotive value chain

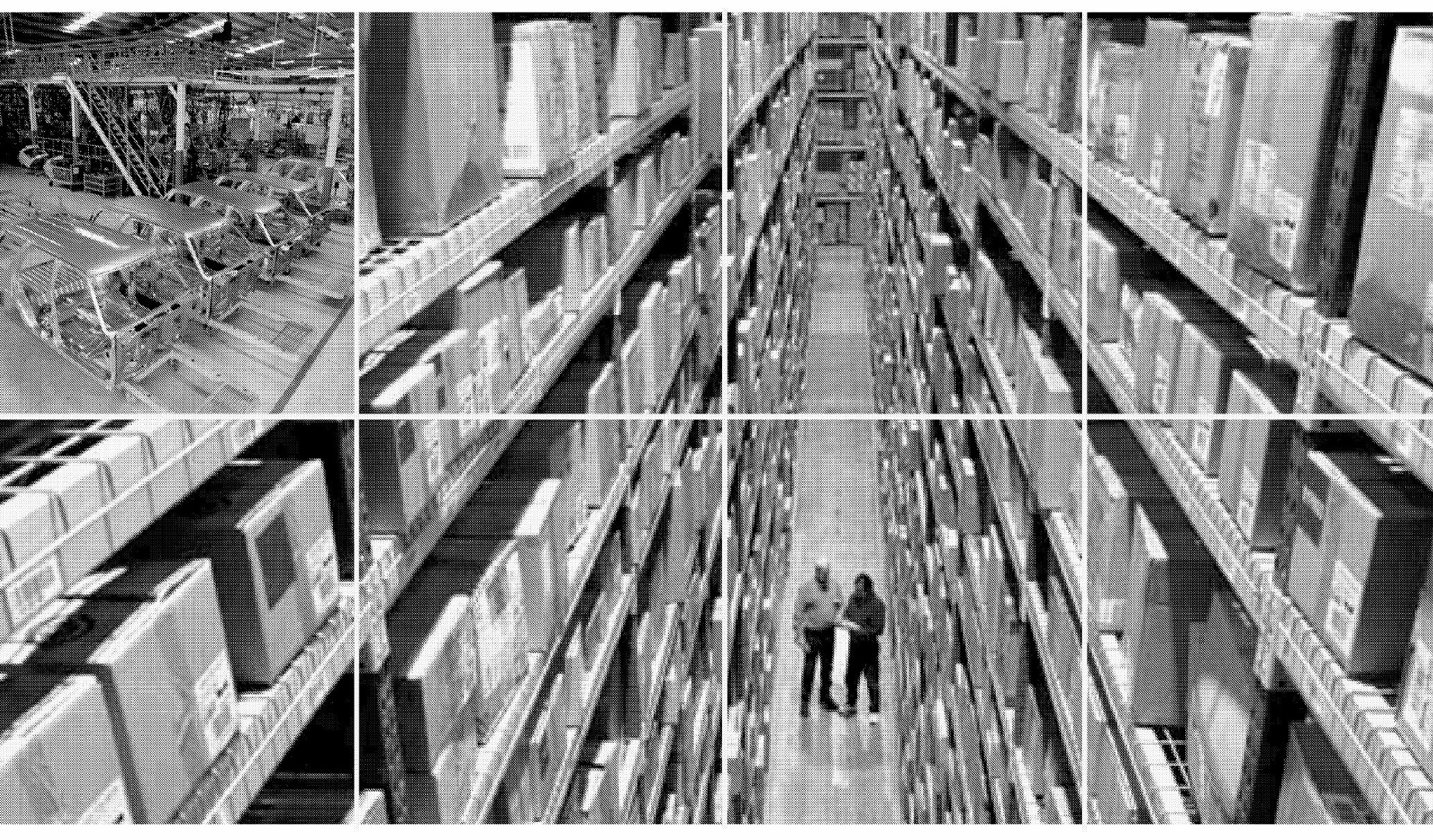

An IBM Institute for Business Value executive brief

In association with

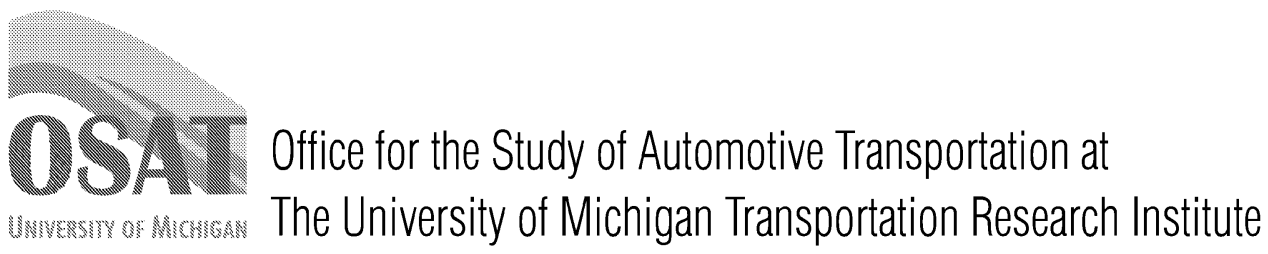


The IBM Institute for Business Value develops fact based strategic insights for senior business executives around critical industry specific and oross-industry issues. This executive brief is based on an in depth study created by the IBM Institute for Business Value. This research is a part of an ongoing commitment by IBM Business Consulling Services to provide analysis and viewpoints that help companies realize business value. You may contact the authors or send an e-mall lo ibv@us.ibm.com for more information.

The University of Michigan's Office for the Study of Automotive Transportation (OSAT), a research unit of the University of Michigan Transpontation Research Institute, has performed research, analysis, and communication activities focused on the automolive industry for nearly 25 years. UMTRI $2004-19$ 


\section{Contents}

1 Introduction

3 SCM in the context of industry challenges

4 Manufacturers act and suppliers respond: Will traditional roles change?

8 Manufacturer and supplier efforts: SCM priorities are evolving

21 Global sourcing: The world gets smaller, and riskier

25 Next steps: The road ahead for manufacturers and suppliers

27 Conclusion: The new competitive realities of the automotive value chain

28 About the authors

29 About IBM Business Consulting Services

29 References

\section{Introduction}

The automotive industry faces one of the most demanding phases of its recent evolution. Fierce competition means that some manufacturers and suppliers will face mergers or acquisitions, or ultimately exiting the business. Manufacturers' and suppliers' responses as they confront these obstacles will determine which companies will still be part of the industry 10 years from now. The challenges manufacturers and suppliers face create conflicting goals as each organization works to meet cost reduction targets, improve quality and improve time to market. Other pressures such as satisfying shareholders, funding steep legacy costs (for example, healthcare and pensions), and cost reduction initiatives affect both manufacturers and suppliers alike. Supply Chain Management (SCM) activities play a significant role in many of these areas.

In previous research into integration and collaboration in the automotive supply chain conducted by the University of Michigan's Office for the Study of Automotive Transportation (OSAT), suppliers were found to be about half way to their goals of integrating their internal processes, and about a quarter of the way to their goals of collaboratively blending internal processes with the business processes of their customers and suppliers. ${ }^{1}$ The somewhat surprising finding that progress in both integration and collaboration for SCM lagged progress in most other company activities led to the current research that focuses on exactly why SCM is trailing these other efforts. Or, to put it simply, why is SCM so hard? To answer this deceptively simple question, OSAT and the IBM Institute for Business Value (IBV) have undertaken a new study to measure the performance and importance of SCM activities, examine current benchmark SCM efforts and the barriers and facilitators to their implementation, and analyze two major SCM activities: manufacturersupplier relations and global sourcing.

One reason for the lag in SCM may be the difficulty of integrating SCM processes across numerous functional areas. Though companies are breaking down organizational barriers among functions by increasing the integration of their internal processes, SCM processes still cross numerous such boundaries, making progress more difficult. Our research examines how executives view these processes. SCM touches nearly all parts of the organization from strategic planning to sales, from marketing to purchasing, and from product development to manufacturing and logistics. The external SCM linkages with both Tier 1 and Tier N suppliers, when placed in the context of hundreds of suppliers located across the globe, clearly compound the complexity both manufacturers and suppliers face as they manage their supply chains (see Figure 1). 
Figure 1. SCM touches nearly all parts of an organization and many outside it.

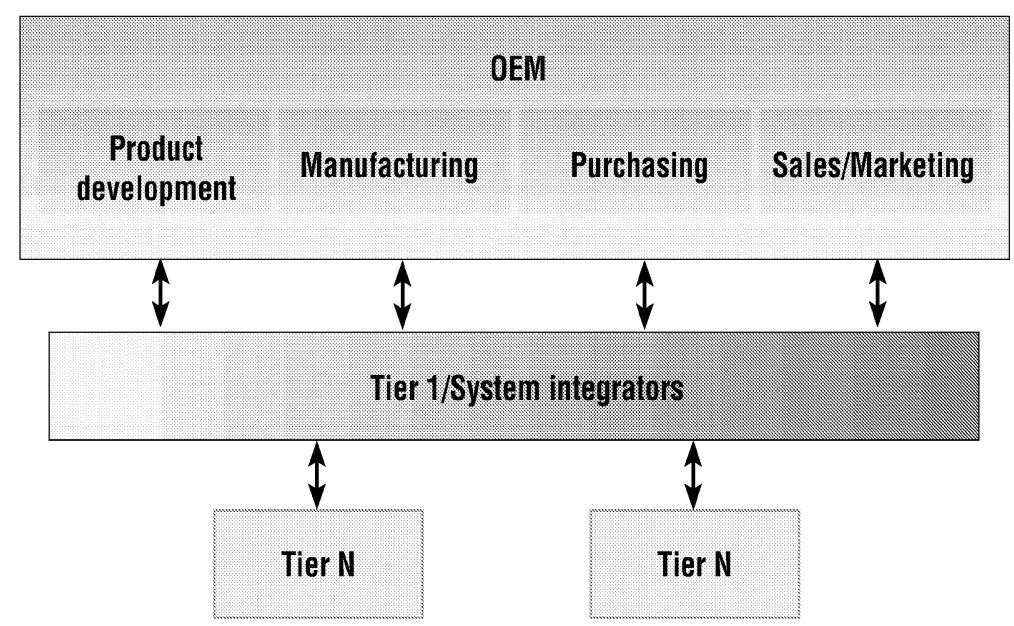

Source: IBM Institute for Business Value and OSAT, 2004.

Our research uncovered three critical issues that will define the future of SCM, and to a large degree the future of the industry:

- Differing manufacturer and supplier relationship models can potentially define which supply chains are more efficient and cost effective.

- Globalization, from the dual perspective of developing a global manufacturing footprint and a global sourcing capability, will challenge even the most sophisticated and well financed companies.

- Complexity, ranging from company cultures and product designs to multiple sourcing and pricing paradigms, will create extremely difficult supply chain management requirements.

Study conclusions are based on interviews with 29 executives from six major global vehicle manufacturers and 10 top tier global suppliers. All of the manufacturer respondents were managers or higher and over half were directors or higher, while over half the supplier respondents were directors or higher ranking executives. ${ }^{2}$ 
"Romb abla bo chorenty support an incrasing number

of lower volwme vehich morers, garl when a hroher level of ophon content and complexiny, is a modamental chalrenge. To ho automobre supply base. Whs challenge resuls in greater prodnd and

process complexify, lower wormes of molvidua pars or ophions, and a kroner lovel of waridion in supply shain Jemand Hows." - Manulacurar respondent

\section{SCM in the context of industry challenges}

Overwhelmingly, manufacturer respondents report that intense cost pressures and managing the global supply chain are the two central issues they will face over the next three to five years. The consolidation of the purchasing function into a global entity has thoroughly changed how manufacturers view their supply base. Many manufacturers and some suppliers have worked to consolidate their purchasing functions into one global team. Some have also implemented portal technology to receive bids from potential suppliers anywhere in the world. The implementation of this technology has raised the level of awareness of the breadth of suppliers available for expanding global operations. Global sourcing, as discussed in more detail later in this report, increases the complexity of managing the supply chain and can create disconnects among high-level company objectives.

Suppliers face challenges similar to their manufacturer customers. Over the last several years, the industry has evolved to include not only local "build-to-print" suppliers but also billion dollar global system integrators capable of providing complete systems - which can pose complex internal integration and external collaboration challenges. This increase in supplier complexity is reflected in the difficulties suppliers report they will face over the next three to five years:

- Increased complexity of manufacturer orders

- Cost and pricing issues

- Risk management in the supply chain

- Collaboration and relationship management in the supply chain.

Suppliers see cost as a major issue as manufacturers increase the complexity of their orders. They also see changing prices and requirements resulting in higher warranty costs. In addition, suppliers must consider the risk inherent in manufacturer demands for global sourcing, especially in the cost of inventory obsolescence. Finally, suppliers see collaboration and relationship management within their own supply base, as well as with customers, as important - particularly because of the role it could play in future supplier rationalization. 
streyone al a suppher w- from suppher CEos w working level people an can po onling ro sed the granulariy of supplo: pertomanese dy company. by commodm, abre by cost." - Manulacluror rospondont
Manufacturers and suppliers have high expectations for SCM as a means to overcome near term challenges, and help them to:

- Collaborate to develop capabilities and solve problems especially in the areas of inventory, scheduling, capacity, and performance visibility

- Optimize inventories across the supply chain

- Manage order complexity and schedule variation.

Manufacturers report that the Internet has enabled better communication across the supply chain by fostering data transparency. Suppliers also view SCM as a way to aid inventory optimization. They report that without SCM tools they would hold higher inventories in the form of safety stock. Finally, suppliers report that visibility programs available through the Internet allow for better continuous improvement efforts because they permit information to flow more quickly to all involved parties.

\section{Manufacturers act and suppliers respond: Will traditional roles change?}

Manufacturers play the dominant role in determining the types of relationships they engage in with suppliers. The common view is that manufacturer actions force a response from the supply chain. But not all manufacturer actions lead to optimized SCM performance. In this section, we consider suppliers' traditional reactive position in relation to their manufacturer customers and examine ways in which they may take a more proactive role in the future of the automotive supply chain.

\section{Manufacturers act}

Executive respondents report that current organizational efforts focused on integrating purchasing and engineering functions in SCM attempt to provide both pricing and innovation advantages for their organizations. Manufacturers' choice of purchasing models has greatly impacted manufacturer and supplier relations, and has helped create the context for today's manufacturer and supplier efforts. In prior OSAT research on manufacturer-supplier relations, we suggested two ways manufacturers relate to their suppliers, the "selection model" and the "development model".

The selection model calls for switching suppliers to meet shifting pricing, innovation or quality targets, and market opportunities. It relies on its suppliers to manage their own productivity and cost improvements. The selection model exploits the momentary advantages of the current market transaction. Suppliers working with manufacturers that utilize the selection model experience constant pressure for cost reductions and productivity improvements, along with the specter of potential "de-sourcing." 
The development model demands evolutionary change by requiring that suppliers continually take part in processes that lead to both cost reduction and productivity improvements. Manufacturers employing the development model see the relationship with the supplier as one of mutual reliance where both work together toward the same goals. As in the selection model, suppliers in the development model are measured by strict performance metrics. However, manufacturers that employ the development model tend to intervene internally with underperforming suppliers to correct their deficiencies instead of de-sourcing them.

The selection and development models present differing cost implications for SCM. Searching the globe for the best price, quality, or innovation requires manufacturers that use the selection model to switch suppliers frequently - and incur higher costs. Suppliers providing strategic components or systems must be integrated into product development systems. This cost is most likely higher for companies employing the selection model, since it takes time to develop the engineering relationships between companies that may not have worked together previously.

However, using the selection model tends to lower the costs of supporting supplier innovation and cost improvement activities - the very premise of this model is the fact that manufacturers spend time and money choosing suppliers that bring the best current price and/or innovation to the table.

Because companies that utilize the development model switch suppliers less often, overall supplier switching and product development integration costs are lower. However, manufacturers must continually benchmark their current supply base against competitors for both cost and innovation, and then work to meet or exceed those benchmarks. This is often a time-consuming and costly process, though companies that use the development model well tend to have systems in place to facilitate the process, and the corporate environment reinforces and rewards purchasing and engineering personnel for their efforts. Another possible disadvantage: pursuing cost reductions collaboratively with the supply base could allow competitors using the same suppliers to gain improved cost-based advantages without the cost of collaboration. 
"Originally we did bid to print. Then we said, 'Le? suppliers do design. 'We considered the enhanced value of bringing suppliers inio the process. We had to have long term relationships. These relationstips led to a "clubby" relationship with the incumbents. In the Iast few years with cost pressures, we had to sitrive for a middle ground." - Manulaclurer respondont
Companies that consistently employ one model or the other make it easier for suppliers to collaborate with them and make longer-term business decisions. Companies that fluctuate between the models can create confusion within the supply base as it becomes unclear to suppliers how they should manage the business relationship. It seems that whenever traditional manufacturers (General Motors, Ford, and DaimlerChrysler) are faced with severe cost pressures, they adhere more strongly to the selection model. But each of the traditional manufacturers has utilized variants of the development model at some point over the past 10 years.

Japanese manufacturers (especially Toyota and Honda) have maintained the development model even though they are faced with the same tough competition. One can argue that the Japanese have not faced the same long-term structural costs that the traditional manufacturers face such as healthcare and pensions. However, since the future success of Japanese manufacturers will be determined by how they prepare to meet these cost pressures, their adherence to the development model may be tested.

The range of SCM activities also includes supplier selection and incorporation into the product development process. Our manufacturer respondents report they are including their suppliers early in the design phase of product development. At this stage of development, every manufacturer is managing the price and innovation trade-off in their decision to outsource or in-source components, which is why many of our manufacturer respondents report introducing purchasing staff earlier in the product development process. Much of this integration began with the decision to outsource large modules or systems to suppliers and led to the creation of "system integrators," supplying directly to the manufacturers. ${ }^{4}$

However, based on our interviews, manufacturers have not given clear directions to suppliers about systems. They do not agree on the definition of a system, and they tend not to have clear system strategies. Manufacturers have evolved their purchasing paradigm to collaborate early in the product development process with suppliers who offer "strategic" components, modules, or systems. Yet, each manufacturer has its own definition of "strategic," so suppliers must understand how each manufacturer views its components. For suppliers, this system uncertainty combines with shifting purchasing patterns to increase the complexity of marketing their components or systems to the manufacturers, as well as to complicate strategic decisions concerning mergers, acquisitions, or divestitures. 
"fis all orer be place

Wron mow as far as how manufasurers are sowrong. Some so comporents, some

do systems. Some of if is based on cost - if moy mink

hey can ger llown to a component, hoy may do hat.

There is cost in mandaning

mora suppliens, but each company is mol looknu al is ha same way. Somernmes if whers aren whm whe same company. Somenmes ir difrers gu cars versus rmors." - Sunplor resondont

"Trablond mandasurers use Infomation lo kake ont cont but ony in lerms of price. The Japanese mand focturers do

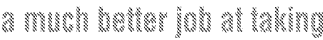
costs out of suppliers Mat can ard in their balance shed. I Is rohing we dont know. The Mapanese just axgente better" ..... Manulachiror resononon
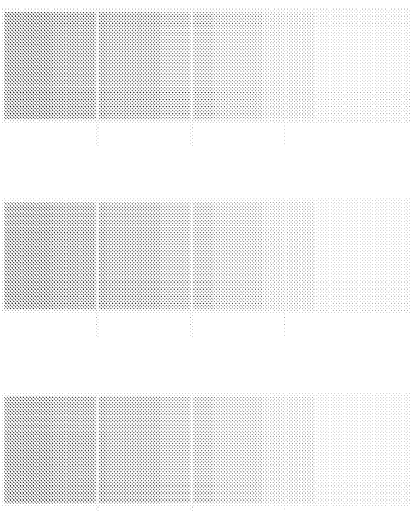

\section{Suppliers respond}

Due to their subordinate role in the relationship, suppliers have traditionally adapted to whatever model manufacturers prefer, but there is a cost to adapting. Some manufacturers have inconsistent purchasing models, either: 1) sourcing, quoting and awarding individual components, 2) sourcing and quoting a complete system, or 3) sourcing and quoting systems but awarding individual components. This situation has led to confusion within the supply base about each company's strategic direction that makes it extremely difficult for suppliers to make long-term business decisions. As price pressures mount and traditional manufacturers revert back to the selection model, suppliers find themselves with increased responsibility for design and development, yet are unable to price their modules and systems to reflect this added cost.

The Japanese manufacturers also expect cost reductions, but they are more willing to aid suppliers and share the savings. Consequently, suppliers find demands for large across-the-board reductions by the traditional manufacturers much more challenging and difficult.

An important difference arises between simply demanding cost reductions using the selection model and understanding the true cost of components using the development model. Though this second effort is very time consuming, one manufacturer sees it as a more effective strategy: "We need to take more true cost out of parts through better benchmarking of part cost-structures. Margins have been shaved off but cost has not come out of the supply chain structure. Success is taking cost out of the supply chain structure, and not just moving margins."

\section{Supplier survival: Difficult choices}

In 2002, Collins and Aikman, an interior supplier, decided to decline business with its largest customer, DaimlerChrysler, on a major high-volume vehicle, because it could not make a profit on the contract that DaimlerChrysler offered them. ${ }^{5}$ Also in 2002, Tower Automotive decided not to bid on its long-standing business making frames for the Ford Explorer, one of the highest volume vehicles in North America, because they could not make a business case for the bid. ${ }^{6}$

In early 2004, two Tier N suppliers to Delphi Automotive, Republic Engineered Products and NSS Technologies, took the drastic step of threatening to withhold delivery of components, potentially shutting down Delphi's and its customers' assembly plants, because they felt their companies would not survive if they had to absorb the recent 30 percent increase in steel prices.?

These situations may be a harbinger of future consolidation in the supply base as some suppliers decide to merge or be acquired in order to better weather these extreme situations, while others simply exit the industry. 
"Ir's true that over time there has been much talk about moving toward systems; but recenly there seems to have been more locus on components. We are trying to understand what custumers are saying and work effectively with them.

The diredion is not as clear as what if seemed to be four io Iive years ago..." - Supolier respondent
Despite the uncertainty in the way manufacturers view components and systems, suppliers today continue their migration from Tier 1 suppliers to system integrators and Tier $\mathrm{N}$ suppliers. Previous OSAT research suggests there will be a 50 percent reduction in Tier 1 suppliers over the next years, as 30 percent become system integrators and 20 percent become what we label Enhanced Tier N (ETN) suppliers. ${ }^{8}$ Suppliers also expect system integrators to gain more power in the supply chain as well as more responsibility for warranty and lifecycle costs. ${ }^{9}$ This expected increase in power and responsibility by suppliers is in conflict with manufacturers' and may lead to situations where manufacturers control component design yet expect suppliers to be responsible for warranty and lifecycle costs.

These strategies seem counter-intuitive given the traditional manufacturers' current purchasing strategies. Adjusting to manufacturers' new purchasing strategies and changing strategic course will take time - especially if that strategy involves becoming less vertically integrated. It may also be that suppliers see that truly understanding a particular system in the vehicle, including the engineering interrelationships among its components, may give them a knowledge advantage that manufacturers find valuable. Finally, a supplier may be proactively charting its own course through product innovation. These suppliers may offer innovative system design and production capability anywhere in the world, and manufacturers that ignore them may find their vehicles at a disadvantage in the marketplace.

\section{Manufacturer and supplier efforts: SCM priorities are evolving}

Many of the changes taking place in SCM are directly related to changes taking place in the industry. The need to improve forecasts and fulfillment stems from the fierce competition among manufacturers as they vie for market share. Supplier management becomes a strategic activity as companies rely on their supply base for continued cost reductions and innovation. Understanding the increased role of SCM within companies and across the industry demands an awareness of how well manufacturers and suppliers are performing SCM-related activities and how important they are to each company's success. Our research used specific SCM activities within each functional area of the business to benchmark current manufacturer and supplier SCM efforts (see Figure 2). The study also focuses on manufacturer and supplier reports of their company's current SCM integration and collaboration efforts - as well as the barriers and facilitators they encounter as they pursue SCM initiatives. 
Figure 2. SCM activities play important roles within a number of functions.

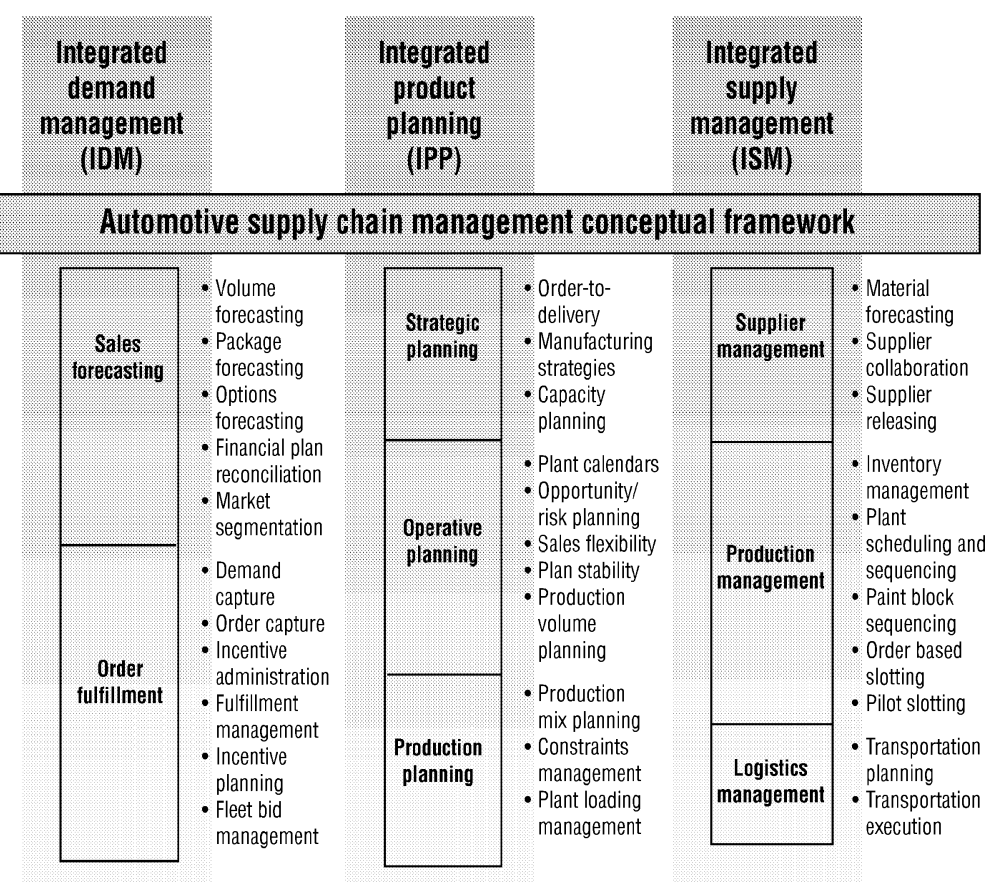

Source: IBM Business Consulting Services, 2004.

\section{Manufacturers on SCM: Executive views}

Manufacturers report significant differences between how well they are performing their SCM activities today and the importance they feel these activities hold for their success (see Figure 3). The level of performance when compared with the importance of the activities is an area for great concern. Indeed, in six of eight activities, led by forecasting, performance rates statistically significantly lower than importance. 
Figure 3. Manufacturers see room for improvement with forecasting having the highest priority.

\section{How well/important?}

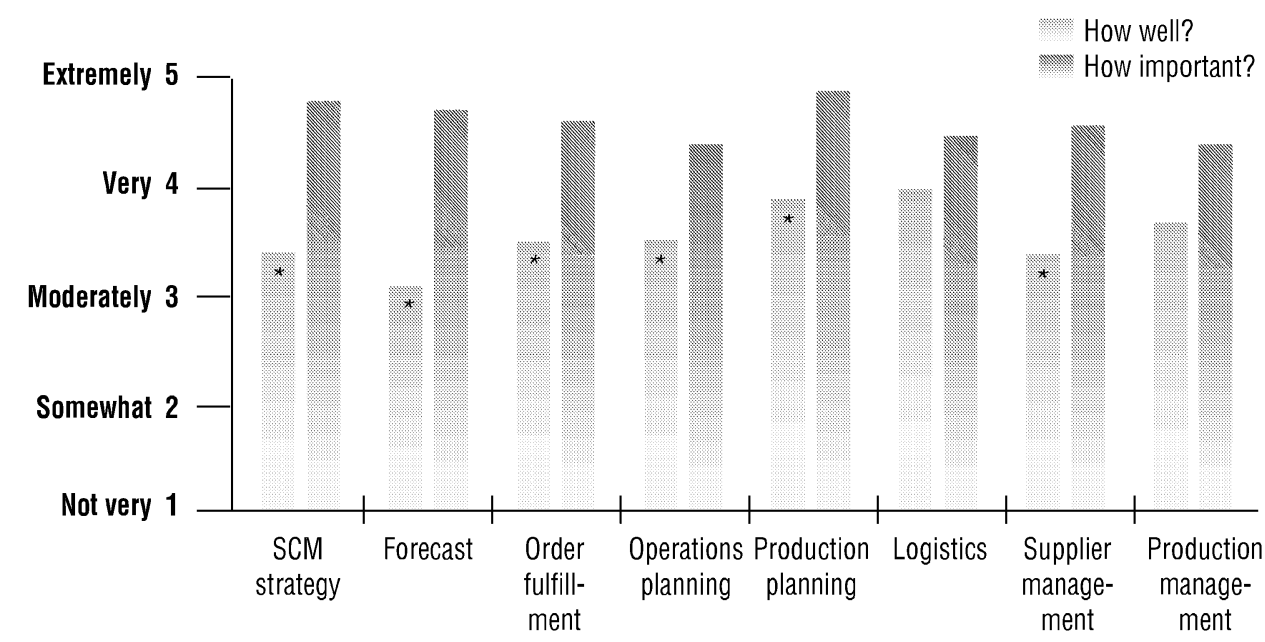

Note: ${ }^{*} p<.1 ; n=7 ;$ All comparisons presented in this report are reliable beyond the 10 percent level $(p<.1)$; many, of course, are much more reliable, reaching beyond the 1 percent level $(p<.01)$.

Source: OSAT, 2004

With the exception of SCM strategy, comparing how well the traditional manufacturers and the Japanese manufacturers rate their SCM performance offers few differences. Though the Japanese manufacturers' SCM efforts are, in general, more evenly developed across the different activities, the ratings of both groups suggest there is ample room for improvement across these areas (see Figure 4).

Figure 4. Except for SCM strategy, traditional and Japanese manufacturers offer similar ratings of their SCM performance.

How well?

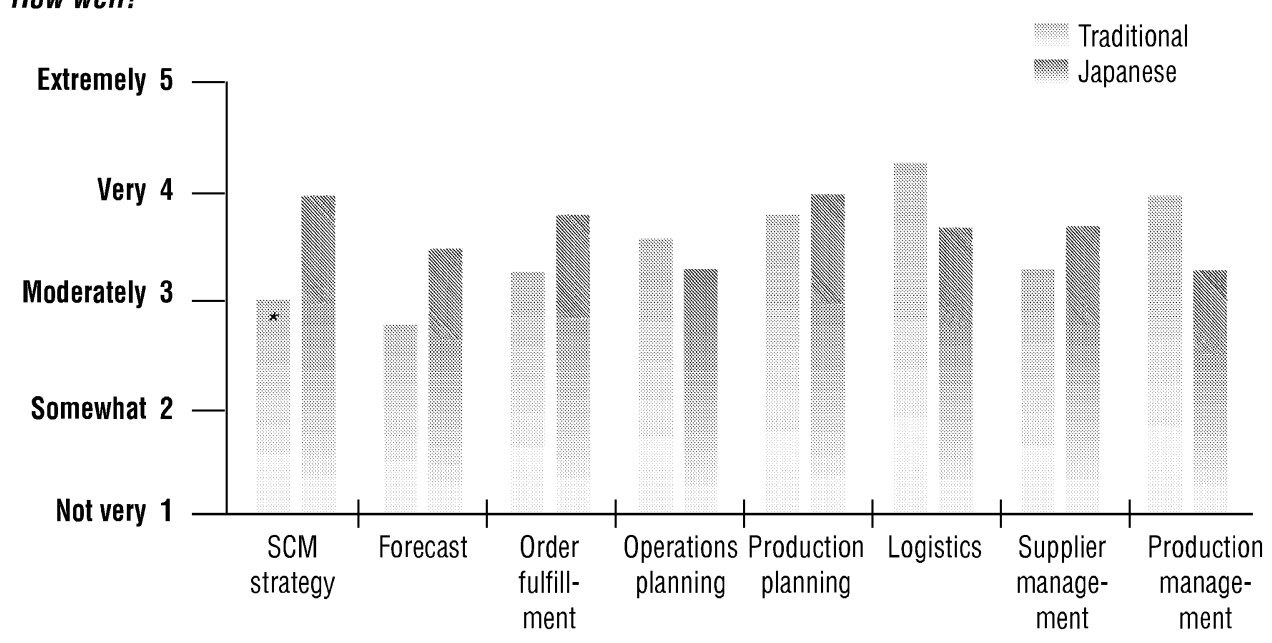

Note: ${ }^{*} p<.1 ; n=7$.

Source: OSAT, 2004 
When we analyzed separately how well the traditional and Japanese manufacturers perform their SCM activities today and the importance they think these activities hold for their company's future success, we found some interesting results. We found significant gaps between the traditional manufacturers' SCM performance and the importance of the activity to their company's success in forecasting, SCM strategy, order fulfillment, production planning, and supplier management. The Japanese manufacturers show a significant gap only in forecasting. Clearly, the marching orders for both sets of manufacturers should emphasize improving forecasts, and for the traditional manufacturers, improving SCM strategy, order fulfillment, production planning, and supplier management as well.

While manufacturers attest that the area that requires the most improvement is forecast accuracy, they report that they perform best in logistics and production planning. This highlights an interesting disconnect: manufacturers continue to struggle to link sales forecasting to suppliers' material requirements. Manufacturers report they are reasonably effective delivering parts to their plants, building vehicles, and delivering them to dealers, but less so at predicting exactly which and how many vehicles to build. This weakness is amplified throughout the supply chain as suppliers across all tiers must purchase materials to produce the highest forecast for each model, yet try to control costs when the original forecast is inevitably lowered.

\section{Improving forecasts: No easy answer}

All manufacturers interviewed view forecasting as their greatest SCM challenge. Forecasting is difficult because manufacturers in the North American market employ a "push" model of production that generates production volumes based more on the need to utilize plant capacity than on the need to build to customer orders. Over the years, this production model has led dealers to maintain large lots of vehicles that must be sold to make way for newer vehicles. Because dealers own the vehicles on their lots, their main incentive is to sell what they have rather than encourage customers to order other vehicles. Indeed, about 80 percent of vehicles are sold off the lot, rather than ordered by consumers. Some vehicles sell easily while others need incentives to sell, but the critical question remains unanswered: "What compromises are customers making when they buy a vehicle?" Given this situation, it is extremely difficult to predict exactly what customers truly want. If manufacturers knew exactly what customers wanted, they could build it and increase customer satisfaction.

Some manufacturer respondents report attempts to develop customer demand-sensing through programs that improve the forecasting of dealers' orders. Others report attempts to gather consumer intelligence from manufacturer Web sites, although identifying consumers who visit Web sites as genuine, qualified buyers continues to be a significant challenge. 
"The sycten has latencies between onder mandagmen, pamming and supply chain sysen execulion. Wo don thave

dynamis connectwiy

ro allow radime araladiry dargs."
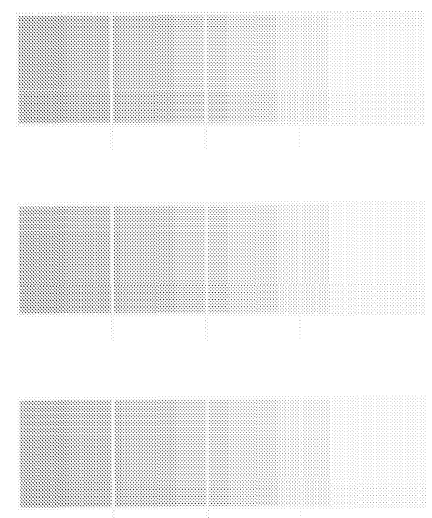

Some manufacturers try to develop more accurate forecasts by limiting the number of engines, options, and colors of their vehicles, thereby reducing the possible number of combinations customers can choose. Dealers can stock nearly all the possible combinations on their lots. Yet, even this method does not yield true buyer wants and needs as customers are still largely limited to purchasing what is available on a dealer's lot.

The "pull" model supports better production forecasts. In this model, manufacturers adjust their production based on the "pull" of individual customer orders. Manufacturers still use initial production forecasts, but adjust production based on orders generated through their dealerships in much the same way that kanban (just-in-time) systems control factory material flow. European and Japanese dealers employ this process in their home countries. Over the years, it has given manufacturers a better understanding of customer preferences, allowing them to devise better initial forecasts. The challenge to introducing this model in North America is that for so long dealers have built their business model on the fact that manufacturers have encouraged them to carry large inventories. Building primarily to customer orders undermines this strategy, as well as the dealer strategy of customer price negotiations.

\section{Order fulfillment: More stumbling blocks}

Some manufacturers see dealers as their customers, and they spoke of their efforts to improve their order fulfillment processes. Although very few manufacturers report developing an "N Day Car" initiative, they see opportunities to improve order fulfillment through "locate-to-order" processes. These allow dealers to find a vehicle for a customer from another dealership.

Another strategy is to allow customers to search inventories of dealerships over the Internet. But most manufacturer Web sites do not allow consumers to configure a vehicle and search all dealer inventories in the area at one time. Instead, consumers must go from dealer Web site to dealer Web site checking each one's inventory. Manufacturers designed their sites this way because larger dealers complained that the Internet put them on equal footing with smaller dealers in spite of their larger investments in vehicle inventories. One manufacturer thinks financial incentives may be necessary to facilitate multi-dealer inventory searches.

Once an order has been placed at a dealership, manufacturers want to improve the process of fulfilling that order either by reducing the time it takes for the vehicle to be built and delivered or by providing realistic and reliable delivery dates. To decrease delivery time, some manufacturers are piloting $24 / 7$ delivery to dealers. To improve the whole process, some state that they need standardized vehicle configuration data across functions, especially realtime data. Manufacturers also see a major technological barrier in developing electronic visibility systems that allow dealers and customers to view their orders at any time in the order process. 
"On rme delvery to the ractory Is excephoraly lon. part shontages are rare. II makes if seen like wo have a pood supply chain. But his is accomplsher by heroes on the inside of the promonalon and invonwores pukside or whe oryanizalion." .... Manuladurer rosonondonl
Manufacturers find major barriers to change in the use of information technology (IT). They report that the IT organization does not respond quickly, often fails to deliver systems when promised, is expensive, and is difficult to coordinate with outsourced IT support. Other challenges arise from the need to continually patch legacy systems, and render the processing, storage, and communication of data fully transparent to the supply chain.

Inventory is still a key hidden cost in the supply chain, and may be increasing. Manufacturer respondents report an inability or unwillingness to measure true costs in the supply chain, especially the cost of inventory. Following a lean manufacturing philosophy, manufacturers have demanded just-in-time (JIT) delivery to their own plants, which hold little or no inventory. However, as the global supply chain lengthens, manufacturers and suppliers alike are recognizing that more inventory in the pipeline becomes necessary to help ensure that plants do not shut down and that unforeseen schedule impacts are decreased.

As an example of the importance inventory visibility plays in the minds of global manufacturers, a recent Economist Corporate Network (ECN) survey conducted among Chinese automotive suppliers reports that visibility of inventory levels in the supply chain is one of the top three requests from the manufacturers. ${ }^{10}$ However, the cost of holding additional inventory is the real issue. Even though the cost of inventory is usually lower earlier in the production chain, one can argue that manufacturers are ultimately transferring the cost of maintaining inventory onto companies that may be the least financially able to bear it. Shifting, rather than eliminating costs, weakens the supply chain.

Not surprisingly, almost all manufacturers are focusing efforts on standardization, utilizing common nomenclature and data formats, and integrating computer systems. They are also focusing on integrating supply chain processes with other functions, such as engineering with purchasing, logistics with manufacturing, or engineering with manufacturing. Integrating functions is a big step toward improving SCM performance, and represents a major shift in manufacturers' thinking. In this approach, manufacturers view the company as a single global organization with uniform metrics, a multifunctional staff, and the standardized tools necessary to facilitate better coordination and communication among a variety of functions. 
"Wre proviom is bal we

have Ime molvanon to

ser wion why prograns:

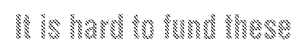

indiatives. Wo already have

good inwornd sarvice levers

and he potental Inentory

sanngy whl onk show my

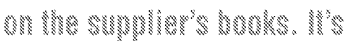

have to show how wa will ges

a price break The morrirs so

not prowde any indentue ror

us as an own to improve."

-..- Manulacturer respondent

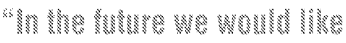

Io have Ther 1 Wdiredional

colaboration and

informaton on inventory

visibriny, and beler

exceplon managernen."

- Manuhodurer respondon
Senior management support and a corporate culture aligned with SCM goals are the main facilitators of change. Another major facilitator is securing the agreement of each division and plant on corporate SCM priorities through frequent meetings where operational leaders review the business cases for these efforts and demonstrate how they are linked to corporate strategy.

But change has not come without difficulty. Organizational uncertainty, complexity, and technology often hinder SCM integration. At the organizational level, manufacturers report confusing messages from top management in a number of areas. These include how the company will work with its suppliers, financial reporting that stresses hitting program targets but suboptimizes the overall enterprise, and high $\mathrm{ROI}$ hurdle rates for basic necessities for integration such as standardization projects. From the manufacturers' point of view, attempts at cross-functional integration create more complex organizations and endeavors to integrate global operations foster potential disconnects within the company.

Manufacturers have taken the first step in electronic collaboration by employing portals to communicate with their suppliers. All manufacturers report that their supplier portal technology has revolutionized how they collaborate with their suppliers. The portal provides one face to all suppliers and functions, and it eliminates the need to call hundreds of suppliers whenever a change occurs. Supplier portals provide some very valuable information to suppliers. They can view their own ratings on delivery, cost, and quality as they are updated. But full collaboration demands a bidirectional transfer of information and knowledge, something that few manufacturers mention when discussing their portals. Manufacturers also describe a number of individual systems they are using to collaborate with their suppliers, such as capacity planning, supplier management, and value management systems.

Manufacturers report that they have better processes for monitoring supplier performance, and that supplier performance data on the portal is used extensively for supplier selection. In particular, manufacturers report they are looking for suppliers with global reach. The metrics that manufacturers use for monitoring supplier performance reflect the push for quantifiable cost reduction, quality, and delivery goals. Manufacturers also report that chosen suppliers have met quality and cost targets, and delivery has been consistently good, although one manufacturer worries about the future logistical challenges of offshore sourcing. 
However, our executive respondents noted two obstacles for collaborative workflow processes: the need to integrate internal legacy systems in order to deliver information to the portal, and accepted industry communication standards such as $\mathrm{XML}$ (extensible markup language) to deliver some information through the portal. Executives also report the need to expand EDI (electronic data interchange), which provides short-term sequencing and mix schedules, to XML-based transactions (Web-EDI). All the manufacturers and most large suppliers already have EDI processes enabled, and they do not see the advantage of moving to Web-EDI. However, a number of manufacturers and suppliers report they are considering WebEDI to connect parts of their supply bases that are not already EDI-enabled.

Security is another major challenge to collaboration for both manufacturers and suppliers. Not only are firewalls needed to protect portals from unauthorized use, but one respondent reports that staff is needed to manage permission to access different parts of the portal because of turnover and job change within the company, as well as at its suppliers.

When comparing manufacturers' collaboration with Tier 1 suppliers to suppliers' collaboration with Tier $\mathrm{N}$ suppliers, it becomes clear that manufacturers feel more strongly about the benefits of technology than do suppliers. Most manufacturer technology efforts are aimed at providing new ways of collaborating.

Suppliers, on the other hand, use technology in efforts to reduce costs and enhance their suppliers' ability to compete. Taking this path is a more arduous one for Tier 1 suppliers, but possibly a more realistic course of action if they are truly to improve their supply chain's performance. Manufacturers looking to technology to provide a "silver bullet" to improve SCM may ultimately be disappointed with the results. 


\section{Portal technology: The next wave of SCM collaboration}

The automotive industry's progression in portals is in line with the general theory of portal evolution (see Figure 5). In the early stages of portals, information is static, giving the viewer summary information about the company, its policies, and contact information. In the next stage, the portal provides more helpful information such as forecasts; supplier cost, quality, and delivery ratings; payment schedules; and more interactive processes such as electronic quoting. But at this stage information is not yet updated in realtime. Updates tend to be in weekly or monthly batch mode. The more advanced stage of portals enables true collaboration through the portal by linking SCM business processes in realtime in:

- Product development: engineering design collaboration with suppliers and engineering change processes

- Sourcing: supplier selection and supplier cost, quality, and delivery ratings

- Supply chain operations: long- and short-term forecasts and schedule information with inventory visibility through radio wave logistics, exception management, purchase order releases, material signals and tracking, shipment notification, and logistics coordination

- Manufacturing: quality monitoring such as Advanced Product Quality Planning (APQP) and Production Part Approval Process (PPAP), continuous improvement projects, and warranty tracking.

In the future, we expect these realtime workflow processes to reduce cycle times dramatically. We also expect the integration of company processes needed to supply information to the portal to provide business intelligence that will help improve executive decision-making processes.

Figure 5. Enabling realtime workflow processes will define advanced portals.

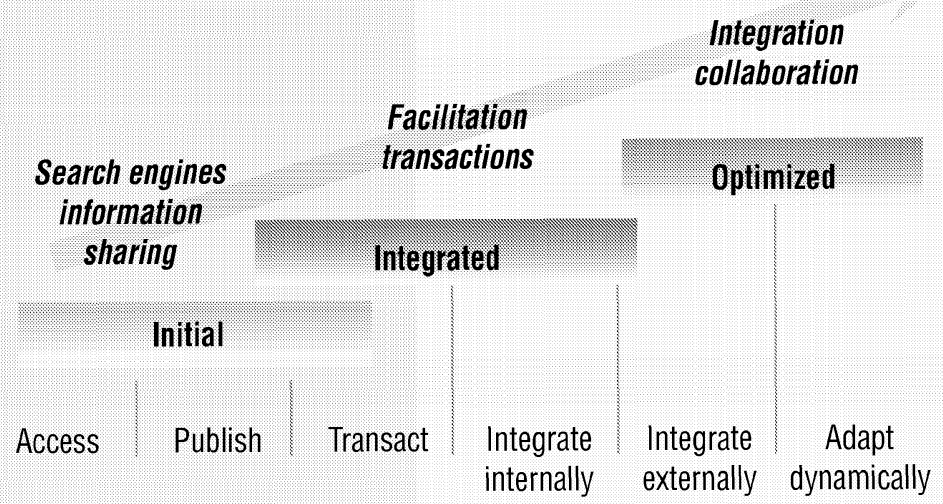




\section{Suppliers on SCM: Executive views}

Our supplier executives consider their performance good across three SCM activities: order fulfillment, production planning, and production management (see Figure 6). They also report four areas where SCM performance rates significantly lower than importance to their companies' overall success: SCM strategy, forecasts, supplier management, and production management. Suppliers' selfassessments are similar to manufacturers' self assessments, with the exception of order fulfillment, where suppliers believe they are performing very well. Manufacturers rate their activity performance lower than they rate its importance in six of eight activities, while suppliers do so in four of eight activities. Also, suppliers rate their performance closer to importance for order fulfillment, operational planning, production planning, and logistics than do manufacturers.

Figure 6. Suppliers perform order fulfillment, production planning, and production management very well, but need to improve on a variety of other measures.

\section{How well/important?}

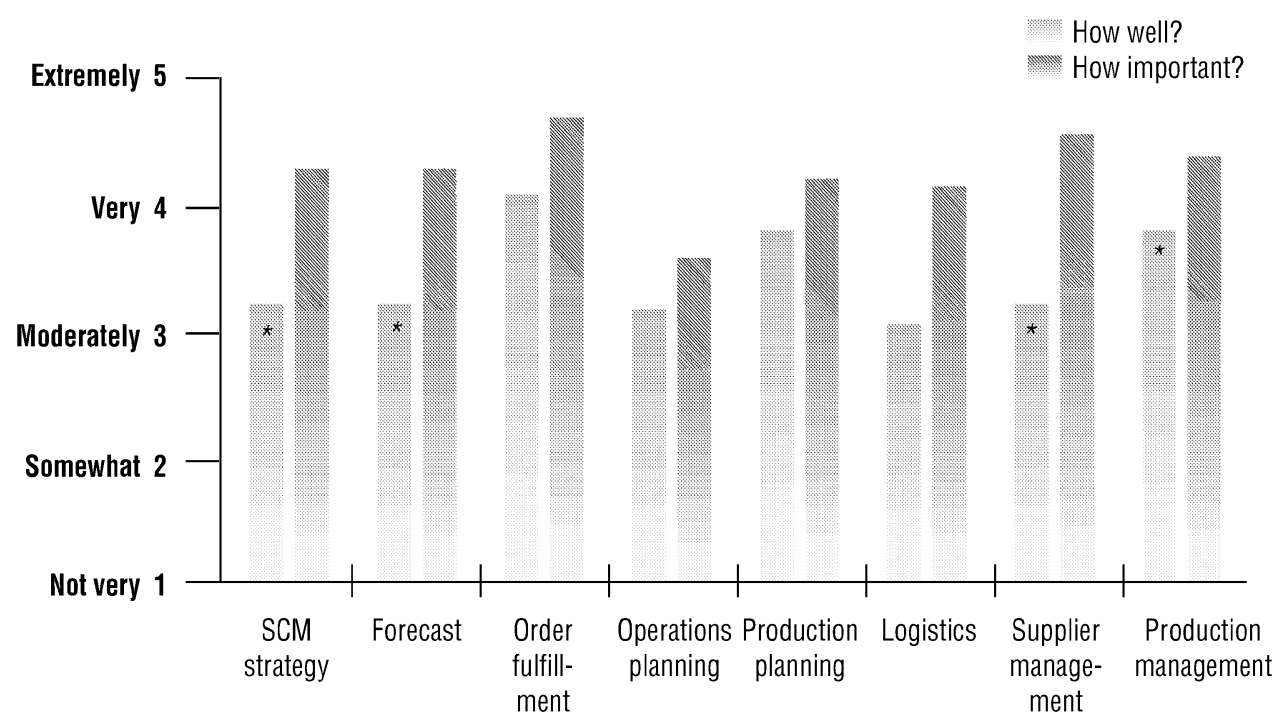

Note: ${ }^{*} p<.1 ; n=9$.

Source: OSAT, 2004 
"Whe grearest mproct isoues are caused by late desinn changes Mat must be

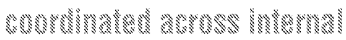
funchons as well as wh? supply chain parmers, lo ensure that he snire supply cham is prepared 10 meet prodwotion dates." -.. Subolier respondont

"Wo have nor recenert benefis by working wh? Imanufachurers. We have not sern any new ideas from hom

mat revul in bendis to us consentwy how we manage a supplier or supply chain. ." -.. Supplier respondont

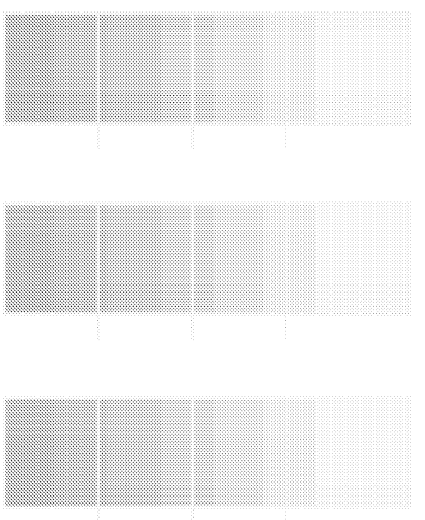

Similar to manufacturers, suppliers report that their main efforts involve integrating SCM processes with other functions inside the company, such as in product development and purchasing where they are merging product data management (PDM) with enterprise resource planning (ERP). One supplier also reports attacking inventory by using a tool that tracks inventory three links deep in the supply chain to see the integrated impact on the total chain. In order to do this, the supplier had to implement common platforms and establish data warehousing for manufacturing, quality, and total inventory.

\section{Suppliers and manufacturers: Collaboration requires trust}

Suppliers do not view their SCM relationships with customers as collaborative. They report that "collaborative" efforts with manufacturers are almost exclusively one way. For suppliers, customer demands require "just-in-case" inventory, compel them to build distribution centers or factories near manufacturer plants, create unique processes instead of developing industrywide standards, and force late design changes that need to be tested before they are released - all of which pose significant timing challenges and add significantly to their costs. Suppliers see design change challenges as both internal and external. Information is transmitted over the Web, but it is not realtime and it is a one way flow from manufacturer to supplier.

Lack of trust is also a major barrier to collaboration. Even manufacturers report that mutual trust is eroded by confusing mixed messages from top executives about interacting with suppliers, generalized supplier resistance to programs based on their previous negative experiences, and a "what's in it for me" mindset among both manufacturers and suppliers. At the same time, suppliers report a serious inability to trust manufacturers as the main obstacle to investing in collaborative efforts with them beyond what is absolutely required. They cite a litany of reasons for this attitude:

- Short-term relationships with manufacturers

- Manufacturers' lack understanding of the supplier's business or its survival

- Manufacturers' shifting strategies and initiatives that make it hard to predict longterm returns

- Short-term industry cost pressures that ignore long-term consequences

- Manufacturers' insistence on costly, unique systems

- Lack of incentives to collaborate. 
"Wo wank rom no she waning lo work on Mrancplants lo grovone wanting lo work on Harsphands becanse of he customer relationship and level of ruse. IN is more of 3 colaboralue relationship." .... Supolign reponolon

"You necuro larger a smaller mumber of supplers lo work Why, and work back hrovgh two ro three lers of he chain lo beremine bow you make the chain lhe most comperwe agains? your competors. People are realning that If Hey nes a smaller number of supphers, Whey oan comminicare more whidly and oasily and hrerofor surne.

They can also work with a smallew muner of sustomers in orter to develop relabionsins."

-... Supplier resonolent
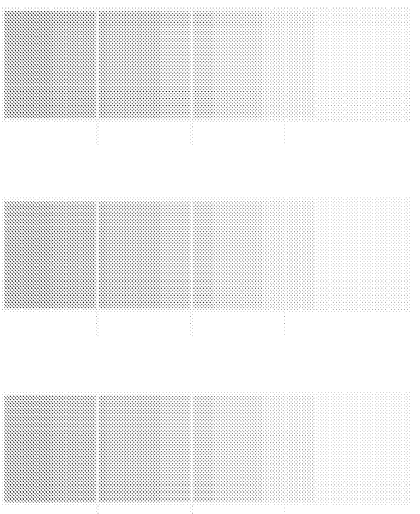

However, suppliers are not completely without hope. They report collaboration does exist with manufacturers that build a relationship based on trust or confidence. They also believe their own efforts to improve and standardize common processes make it easier for them to collaborate with customers. Suppliers suggest the need for manufacturers to adopt common systems using standardized integrated data to improve collaboration. For themselves, suppliers report that colocating with customers, consolidating their design activities under one roof, and integrating products and customers across the entire company will facilitate customer collaboration. But they also express a desire to keep customers at "arm's length," and the necessity of piloting customer projects and demonstrating results before participating in new business.

\section{Suppliers and the supply base: Working toward effective collaboration}

Suppliers confront a number of barriers to collaborating with their supply base. First, they report they currently work with too many suppliers, and believe that some rationalization must take place in their supply base. Respondents report that in some cases rationalization not only means reducing current suppliers, but also searching globally for new, more qualified suppliers. Suppliers believe that rationalizing their supply base will improve communications and allow them to develop better relationships with fewer suppliers. These suppliers are described by one supplier who notes, "Smart suppliers are proactive about what's new and improved. We looked into the future and saw things the customer would not accept before they became problems. Now our suppliers are doing it. We are driving it a bit, but 65 percent of our suppliers are proactive."

Another barrier to supply base collaboration is that manufacturer-designated Tier $\mathrm{N}$ suppliers are chosen by the manufacturers, and do not always participate in supplier improvement programs designed by Tier 1 suppliers. This situation makes it difficult for Tier 1 suppliers to develop their own supply chains. Manufacturer-designated suppliers often make changes to parts based on direct communication with the manufacturer rather than through the Tier 1 supplier. This poses a serious problem for Tier 1 suppliers as they are unable keep the changes coordinated in their own product development system.

Suppliers report that facilitating cross-functional integration requires training people to understand cross-functional dependencies and impacts as well as the technical and cost trade-offs. However, barriers arise if the company is not aligned to support SCM, or lacks the technological tools to support cross-functional integration. 
"With too many suppliers on each commodity, we need lo reduce our base.... It is hard

Io do Kaizen (continuous

improvement) with too many suppliers. We have fwo to three times as many as we need. We won't ger the benefit across too large of a base." -... Supplier respondent
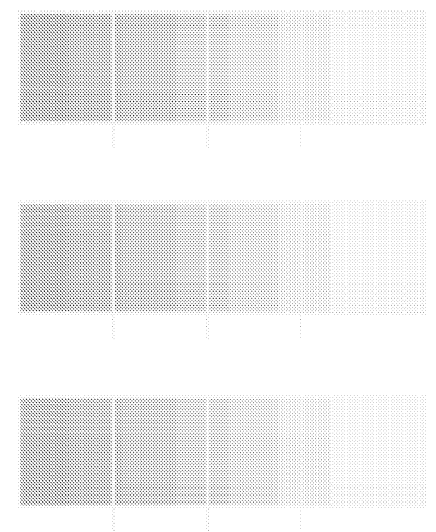

Suppliers note a number of technical and organizational facilitators of supplier collaboration, including electronic requests for quotes (RFQs), EDI, and realtime performance monitoring systems. However, the move to more electronic collaboration requires user administrators at each company to monitor permissions to participate in programs. This and other security positions add to the cost of electronic collaboration. Suppliers also believe that reorganizing their internal, cross-functional groups (for example, centralizing the purchasing function and linking it to engineering) will aid collaboration. Including Tier $\mathrm{N}$ suppliers in product development and using common processes were also noted as facilitators of collaboration in the supply chain.

Supplier SCM efforts with their supply chain often extend beyond electronic collaboration. Some suppliers view SCM as the opportunity to collaborate with the supply chain in ways that some of their customers may not. One supplier states, "The view of managing the entire value stream is potentially the foundation for doing this work. If you look at it as unrelated buy/sell transactions down the chain, you are working in the old model. You need to look at the integrated value chain to make improvements. You need to look at interrelated waste and process identification." Some system integrators are making progress in this model by testing systems to better understand and control inventory within their supply chains, and some are also working with their suppliers to develop their business.

Suppliers are not ignoring the opportunities presented by developing electronic data sharing links with their supply base. Like their customers, they have focused internally for many years and only now, because of the Internet, are they exploring their external options. Portal technology is paying dividends by allowing suppliers to connect with the Tier $\mathrm{N}$ supply base in effective ways that were not possible in the past. Suppliers are now monitoring their suppliers' performance using lean processes like supplier scorecards and total cost management. They are also collaborating with their suppliers through electronic kanbans, auto-messaging and inventory visualization, and in at least one case, are offering bidirectional collaboration with suppliers.

Tier 1 suppliers are in a unique position in the supply chain because they can learn from the good and bad examples of their multiple customers, such as usage of the selection and development models with their supply chain. Suppliers that can transfer the good examples they glean from their customers to their supply chain may be better able to control their costs. While suppliers are passing some of the price-down pressure from their customers to their own supply base, at least one supplier sees a long-term solution, "Longer-term contractual relationships and partnering in continuous improvement efforts have allowed coordinated activities to reduce cost, rather than merely negotiating around the distribution of profits between supply chain partners." 
"Suppliers have total visidility of our shop floor Inventory. They can respond based on existing orders.

We are moving from a push

lo a pull system that is collaboralive...and has ... an issue resoivion system. --. Suppler respondent
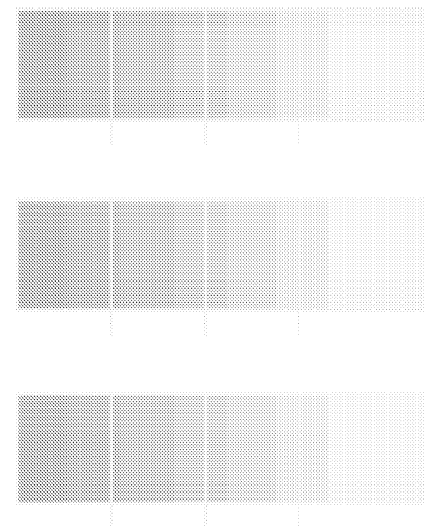

\section{Global Sourcing: The world becomes smaller, and riskier}

The continued growth of the auto industry in Asia, Central Europe and other developing areas shows that manufacturers are still in the process of understanding and developing their global capabilities - as well as communicating and coordinating these opportunities with their suppliers. As one manufacturer noted, "Global models with global coordination are complicated. Our global organization is trying to coordinate these activities. We are now coordinating manufacturing worldwide, and we need to create joint global strategies with suppliers."

Company sourcing strategies are now made with the global industry in mind. Both manufacturers and suppliers make key global sourcing decisions, whether they choose to support their domestic or foreign activities. Theoretically, manufacturers, system integrators, Tier 1 suppliers, and Tier $\mathrm{N}$ suppliers all have the same options." They can enter a foreign market by building in that market, perhaps exporting some product to build economies of scale. They can import from countries, within or outside their trading pact, or they can import from a country outside the trading pact. They can also participate in joint ventures with local firms to develop their local activities. Some manufacturers are "requesting" that key suppliers locate in the same country, and even demanding they site their plants in a supplier park adjacent to the assembly plant. This situation substantially reduces logistics costs for local procurement, but it forces suppliers to compete against the manufacturer and other suppliers in the same labor pool. It may also limit suppliers' opportunities to supply other automotive customers located elsewhere.

Previous OSAT research shows that the decision to build locally or import is not a simple one. ${ }^{12}$ Depending on the size, weight, and value of the component and a company's current global manufacturing footprint, we found that importing to support the local plant was often more cost-effective. Japanese suppliers have built plants in North America to support the growing needs of the Japanese manufacturers there, as well as for the opportunity to supply the traditional manufacturers - and suppliers can be expected to build plants in China for much the same reasons. But one supplier suggested purchasing from China before building there, "If you build a new plant you have to build the cost structure on a 10-year return rather than a 20-year return. Companies should consider entering China or any new country with purchasing activity first. You can do direct investment or sales, but procurement is an easy, low investment way to enter a market and develop relationships. You typically have backup sources, and you have leverage in the transaction." 
"We need ro irentiv glond sourcing opporwnhios and late Mrose ireas lo kne wrrent supply base. We need lo give Mem an opporwnify lo grow rather than mol rewowne me buriness." -... Shonler resondent

"We have lo ensure we have

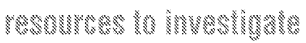
sobal sourcing and manage our jlobal spend. We view the anire world as the supply base, nol Yust a reyion. Who

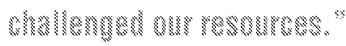

-..- Manulaclurer respondent
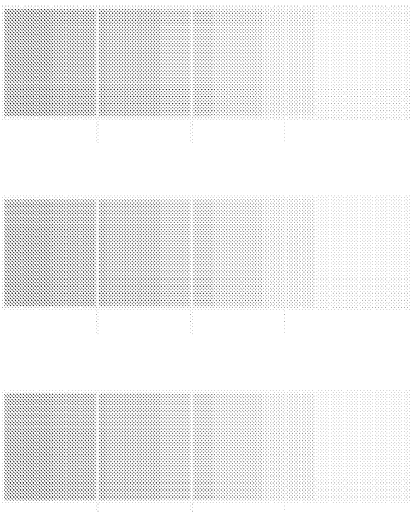

\section{Globalization: The rush to Asia}

Although Thailand has been considered a major potential production location, some manufacturers and many suppliers have awaited the opening of China, and recently have been making major direct investments there. Its market potential and relatively low production costs make China attractive for automotive investments. Some manufacturers and suppliers had already established production in China, but recent investment has increased substantially, with about US\$8 billion invested in the vehicle sector in China from $2000-2002 .^{13}$ It is obvious that its market is what puts China on the top of every company's list of potential investments. At its peak, Thailand built about 500,000 vehicles a year. In 2003, China built almost 4.6 million vehicles, making it the fourth largest vehicle producer in the world following the U.S., Japan, and Germany. ${ }^{14}$

Yet some manufacturers and suppliers remain skeptical. One supplier executive noted, "My purchasing manager had to 'see' what I was talking about. After some visits, he became a convert. I believe that managers have to see and touch factories and see the pride in other countries and regions that they can do a good job." Even some manufacturers have required convincing. After an eye opening trip by a high ranking executive, one manufacturer decided to increase its investment tenfold.

All of the manufacturers and suppliers we interviewed source globally, but each company employed different strategies and had different experiences. Manufacturers believe that they have learned a lot from their previous experiences in global sourcing and from the amount of global information available today. Both manufacturers and suppliers report that global sourcing led them to organize procurement into a single, global purchasing function, where global prices are benchmarked in order to leverage local cost structures. Global sourcing has made manufacturers and suppliers more proactive in managing their supply chains across continents, forcing them to use common SCM systems in order to speed supplier collaboration and rethink how resources are utilized.

These global sourcing strategies, which are part of implementing global SCM, constitute one of the biggest challenges and significant risks facing manufacturers - and by extension their suppliers - over the next three to five years. One supplier described the situation very well, "As manufacturers demand that suppliers source a greater quantity of supplied goods from emerging markets in order to obtain economic incentives for in-market expansions, this process will result in longer, less flexible supply chains that will be more susceptible to volatility." 
"Becanss we are rying in Get he par hom Eastern European cormuries, Mere is a kind of parts lowism, where parts may be manufactured in Poland, pasken in Mre Grent Repunho and roued Mrough Mungary, before they are delvered to mo plant ror he assembry procers, srateand

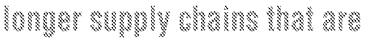
more complyoded:" -Manulaturer repondon?
Companies attempting to go global take on enormous strategic challenges, including the creation of a comprehensive plan for global activities such as product strategy, product development, sourcing, and manufacturing. This includes understanding and managing risk by thoroughly researching new locations and understanding the supply chain's capabilities. Both manufacturers and supplier respondents report significant SCM risks and challenges:

Strategic decisions about global sourcing are complicated by company structures. Manufacturers and suppliers that were originally made up of separate companies crossing different geographies and using separate balance sheets are particularly challenged in merging their global spend under the umbrella of a global purchasing division. Both groups include examples of companies that are still in the process of integrating their internal divisions under one global purchasing organization. This change represents a major shift in corporate philosophy that sometimes meets with internal resistance, slowing progress.

Balancing price versus total cost of components continues to be a challenge. Global sourcing makes the SCM challenge of understanding the true cost of a component within the context of the entire supply chain even more difficult and complex to comprehend. One supplier reports that the challenge of global sourcing is "Finding the right balance between what is locally supplied and what should be moved from other countries. We must make decisions for the right reasons. It may be possible to get a lower price, but maybe there is no real total cost reduction. This occurs if you are looking only at price instead of total cost."

Global sourcing has led to increased complexity in logistics.

Though most manufacturers and suppliers report that global sourcing has decreased the cost of components, many report they face logistical challenges. Respondents noted that some suppliers take on all of the cost and responsibility of delivery, including shipping, tariffs and customs. Some suppliers feel the need to implement complex tracking systems in order to manage overall global logistics and respond to supply chain hiccups or emergencies more quickly. 
Long lead times in shipping and delivery hinder a company's ability to make engineering changes late in the development program or once production has begun. Changes can be made quickly via electronic communication, but a six-week supply line from China, for example, often means that six weeks' worth of shipped product is no longer useable. More than one supplier noted that some manufacturers have not taken this obsolescence cost into account when they consider global sourcing. Manufacturers' changing schedules also conflict with the long lead times required in global supply. One supplier stated that this is particularly true for components where volumes change often, such as interior components.

Increased inventory is needed to manage possible disruptions.

One of the primary requirements of manufacturers is that suppliers not shut down a production plant because of a lack of parts. To avoid this, suppliers must carry their own "risk insurance," which increases costs. As one supplier reports, "We manage the risk either through additional inventory, having backup plants, or identifying other plants to decrease risk. We warehouse a minimum of 30 days inventory, and then we use air freight if necessary." The inventory cost incurred in the supply chain must be considered as part of the total cost of a component.

An unknown Tier $N$ supply base creates uncertainty when sourcing from companies in other countries.

The risk of companies lower in the supply chain disrupting the entire supply chain is a cause for concern and usually translates into higher levels of "safety stock". Not knowing these other supply chain participants may also create safety and warranty issues related to using proper testing and validation procedures. Despite these potential problems, only a couple of executives noted decreased quality as a challenge for global sourcing. One executive noted that while quality usually falls when introducing new global suppliers, it then rebounds.

\section{Communication and geographical challenges cannot be overestimated.} Working with companies from various countries poses challenges to SCM lead times. As one manufacturer reports, "When we started to globalize, we would have four different countries and languages represented at a meeting, but only about 50 percent of what was said was understood by all. It was very slow. We needed a common understanding of terms and concepts. Standardization and common understanding are the challenges." Executives also report the need to improve information flow and to clarify roles and responsibilities. To do this, companies must recognize how different companies in different geographies work - which takes time. Manufacturer executives report that this phase demands constant face-toface monitoring. 
Some sourcing tradeoffs are unique to North American manufacturers and suppliers. There are two additional challenges in global sourcing specific to North American production. First, North American Free Trade Agreement (NAFTA) content will decrease as suppliers source overseas, and that can create problems for duty-free movement within NAFTA. Second, global sourcing can interfere with developing minority suppliers. As one supplier stated, "Developing minority suppliers is a difficult challenge while looking at low-cost countries. It is very difficult to do both. Business is given on cost, not on the combined rating that includes minority sourcing, yet minority sourcing does affect our supplier ratings."

The combination of these risks highlights the increased complexity of global sourcing and illustrates an important potential disconnect among company objectives. How does a successful company balance its risks and reconcile its objectives? One manufacturer interviewee reports some of the frustration personnel feel when presented with conflicting goals: "I see the challenge as doing complex global sourcing while minimizing cost overall. Constant juggling is our biggest challenge. We are asked to build whatever model mix no matter what the leadtime. This is hard to pull off with lean inventories. These demands are in conflict with each other."

\section{Next Steps: The road ahead for manufacturers and suppliers}

How can today's manufacturers and suppliers improved but strained supply chain relationships contend with mounting organizational and marketplace pressures and remain competitive, as globalization offers new opportunities for, as well as challenges to, their success? Our study findings yielded several key success factors that both manufacturers and suppliers should consider as they drive toward a more efficient and effective future in SCM.

Manufacturer and supplier relationships. Understanding manufacturer-supplier relations over the past 10 years provides the context for understanding the state of supply chain management today. The challenge of marketing products to manufacturers with shifting purchasing practices and relationship models makes it difficult to make strategic company decisions. Based on our findings concerning manufacturersupplier relations, successful companies will:

- Choose customers or suppliers that match their own corporate attitudes in order to reduce the complexity of managing contentious relationships

- Balance complexity in product variation with the need to control inventory costs in the supply chain 
- Understand the value "strategic" suppliers bring to their company and balance that with a continuous scan of the changing supplier universe for process or product innovation

- Resist the urge to treat their suppliers as their customers treat them, where a lack of trust in relationships inhibits improved SCM performance

- Refuse to "shop" supplier designs in order to maintain the trust needed in the relationship and avoiding suppliers withholding innovation

- Factor the cost of system research and development into bids

- Understand the generally unrecognized costs of switching suppliers, integrating suppliers into product development systems, and monitoring supplier innovation and cost improvement activities

- Work with suppliers to reduce costs, without then making demands for additional price reductions.

Evolving SCM efforts. Manufacturer and supplier SCM efforts represent opportunities for success and failure. Companies that clearly understand and overcome the challenges these efforts present can reap the benefits these efforts can provide, while companies looking for "quick fixes" may find themselves with little return on their investments. Based on our findings concerning current SCM efforts, successful companies will:

- Make major efforts to better link forecasts to material requests in order to control costs and improve customer satisfaction and loyalty

- Integrate functions across SCM to improve performance, reduce organizational complexity, and reinforce consistent organizational cultures

- Use portal technology to integrate processes internally, as well as to collaborate with and monitor suppliers

- Rationalize their supply bases to allow for better integration of their suppliers into product development and improved cost reduction opportunities

- Improve their supply chains by combining organizational changes with technical tools. 
Globalization. Global sourcing provides another important context for understanding SCM decisions by both manufacturers and suppliers. Both groups are heavily involved in making strategic decisions concerning global sourcing. Based on our analysis of manufacturer and supplier views on this topic, successful companies will:

- Develop proactive strategies based on building plants in countries that offer local market potential as well as export opportunities, rather than chasing the lowest piece price around the world

- Integrate global purchasing resources to develop a breadth of qualified suppliers

- Understand the numerous risks involved in global sourcing: product obsolescence and inventory costs can escalate, while supply chain speed and flexibility can decrease

- Use Internet-based visibility programs to closely track shipments and inventory levels across the supply chain and allow companies to manage their more complicated global logistics

- Recognize the need to qualify Tier $\mathrm{N}$ suppliers located in emerging markets in order to avoid potential warranty claims

- Prioritize company goals while recognizing the conflicts those goals, such as low cost, low inventories, and short lead times, impose on the supply chain.

\section{Conclusion: The new competitive realities of the automotive value chain}

Manufacturers and all tiers of the supply chain have an opportunity to shape the future SCM model. Assessing whether the selection or development model for SCM offers a real competitive advantage can be difficult because of the complex issues surrounding company success. Other variables, such as product offerings and timing, innovation based on internal R\&D, organizational structure and response to challenges, currency exchange rates and global competition can all, at times, contribute to the success or failure of a company. But how companies manage their supply chains in the context of these challenges can be an important determinate in that outcome.

Current relations between manufacturers and suppliers are not yielding significant collaborative gains for the supply chain. Manufacturers are generally very satisfied with supplier performance, yet many suppliers view their relations with manufacturers as a marriage of convenience - yielding only what is required, rather than what is desired. Manufacturers that can find ways of generating true collaboration with their supply chain, especially with increasing global demands, may be able to overcome excess cost in the system. At the same time, they may harness the energy and skills of the truly collaborative supply chain to the mutual benefit of their suppliers, themselves, and their customers. 
"Even Mnowgh we redneed our suppliers, below he

Virst Vier Mere is a mass of spachetr undemeath. Wo ried fo map outhe suppliers of some of wur hrop hier and It pess realy comphraled

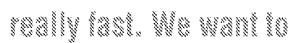
delepate responsibiny to our suppliars, but a the ghe of he ray wa hay lo lo imwolven since is is

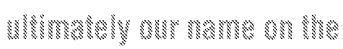
ghroprodust." -.Manulaclurer respondont
Suppliers have long played a passive role in supply chain relationships. In the future, they may have to break out of this traditional reactive role and leverage their knowledge, expertise and innovation capabilities. They may be able to form more collaborative supply chain relationships with both their customers and their own supply base.

Why is it so difficult to implement SCM? Two words: increasing complexity. Even as automotive companies strive to change, the marketplace acquires new facets and imposes demands that must be addressed. SCM crosses numerous internal and external boundaries, and we find manufacturers making serious efforts to integrate their SCM processes internally, but with far less attention to and success at collaborating in SCM with their suppliers. In particular we find manufacturer SCM efforts often increase the complexity of SCM to the point where it conflicts with theirs and their suppliers' main business and organizational goals. The comparative ability to master the complexity of SCM is truly the new competitive reality and challenge that will determine which supply chains ultimately succeed.

\section{About the authors}

Bruce M. Belzowski is a Senior Research Associate at the University of Michigan Transportation Research Institute's Office for the Study of Automotive Transportation (OSAT). He can be reached at bbl@umich.edu.

Michael S. Flynn is a Research Scientist and Director of the University of Michigan Transportation Research Institute's Office for the Study of Automotive Transportation (OSAT). He can be reached at mikeflyn@umichedu.

Morgan Edwards is an OSAT Associate and a retired director of Ford Motor Company. He can be reached at mhesoe@cs.com.

Linda Ban leads the Global Industrial Team for the IBM Institute for Business Value and is an Associate Partner within the IBM Business Consulting Services Automotive Team. She can be reached at iban@usibm.com.

Gregory Martin is the IBM Business Consulting Services leader for the Automotive Supply Chain Strategy practice. He can be reached at gkmartin@us.ibm.com

\section{Acknowledgments}

The members of the OSAT and IBM teams would like to thank the many automotive executives who took the time to participate in our interviews. We are especially grateful for the time and insight they volunteered in support of our efforts.

We would also like to thank the following individuals for their important contributions to our efforts: M. Lee Burge, Jan Eveswell, Mark Ostroth, and Amy Grude of OSAT; Monica Milla of UMTRI, and Marc Bourde, Olivier Payraud and Hansjoerg Fromm of IBM. 


\section{About IBM Business Consulting Services}

With consultants and professional staff in more than 160 countries globally, IBM Business Consulting Services provides clients with business process and industry expertise, a deep understanding of technology solutions that address specific industry issues, and the ability to design, build and run those solutions in a way that delivers bottom-line business value.

\section{References}

1 Belzowski, B, M. Flynn, M. Sims, J. McGlynn, and P. Hebeler. "Destroying Boundaries: Integration and Collaboration in the Automotive Supply Chain." The University of Michigan Transportation Research Institute, Ann Arbor, and Oracle Corporation, 2003.

2 It is interesting that because our questions crossed so many functional boundaries, many companies had more than one respondent participate in the interview. This was particularly the case for the manufacturers. So, instead of interviewing 16 $(6+10)$ people, we interviewed 29.

3 Flynn, M., B. Belzowski, B. Bluestein, M. Ger, M. Tuerks, and J. Waraniak. "The 21st Century Supply Chain, The Changing Roles, Responsibilities, and Relationships in the Automotive Industry." The University of Michigan Transportation Research Institute, Ann Arbor, and A.T. Kearney, Inc, 1996.

${ }^{4}$ OSAT defines a system integrator as a module/system supplier direct to assembly and Tier 1 as a material, part, or component supplier, also direct to assembly. OSAT defines Enhanced Tier $\mathrm{N}$ suppliers as former Tier 1 suppliers that supply material, parts, or components to system integrators or Tier 1 suppliers.

5 "Collins and Aikman Wins Ford Deal." Automotive News, October 13, 2003.

6 "Tower Quits Explorer Frame Program." Automotive News, December 23, 2002.

7 "Delphi, Parts Maker Go to Court." Automotive News, March 22, 2004.

8 Belzowski, Flynn, Sims, McGlynn, and Hebeler. "Destroying Boundaries: Integration and Collaboration in the Automotive Supply Chain." The University of Michigan Transportation Research Institute, Ann Arbor, and Oracle Corporation, 2003.

9 lbid.

10 "China auto suppliers survey." Economist Corporate Network Study, April, 2004.

${ }^{11}$ In reality smaller suppliers have fewer options.

${ }^{12}$ Flynn, M., S. McAlinden, K. Hill, K. Alkire, and M. Edwards. "Cars, Capacity, and Competition in the 21st Century." Michigan University, Ann Arbor, Transportation Research Institute, Office for the Study of Automotive Transportation, Ann Arbor, Michigan, 2000.

${ }^{13}$ China Automotive Industry Yearbooks, 2001-2003.

${ }^{14}$ China Business Update, 2003: A Year of Record Growth for Car Output and Sales, January 15, 2004. 
C Copyright IBM Corporation 2004

IBM Global Services

Route 100

Somers, NY 10589

U.S.A.

Produced in the United States of America 06-04

All Rights Reserved

$\mathrm{IBM}$ and the IBM logo are registered trademarks of International Business Machines Corporation in the United States, other countries, or both.

Other company, product and service names may be trademarks or service marks of others

References in this publication to IBM products and services do not imply that IBM intends to make them available in all countries in which IBM operates. 